\title{
RECOMENDACIONES BIBLIOGRÁFICAS E INTERCAMBIO ENTRE LECTORES EN EL JARDÍN DE INFANTES
}

\section{María Claudia Molinari*}

En las distintas secciones del jardín de infantes es posible organizar acciones sistemáticas que inicien a los niños en las prácticas sociales de lectura y escritura. Desde estas acciones tempranas, formarse como usuarios de la lengua escrita supone resolver situaciones complejas, diversas, con claros propósitos comunicativos.

"El Club de Lectores es una de las propuestas que cumple con estas características. Nuclea una serie de situaciones en torno a las bibliotecas de sala, donde se propone la lectura sistemática de textos ficcionales y no ficcionales y un amplio intercambio de opiniones y recomendaciones entre niños. En función de estos intercambios, se desarrollan actividades específicas de escritura en las cuales, expresándose como lectores, los chicos también aprenden a escribir. En todos los casos, son situaciones típicas de interacción entre lectores-escritores, donde los grupos de 3, 4 y 5 años resuelven problemas como usuarios de manera individual, con su grupo, la maestra, las familias, con otros grupos de niños y docentes". ${ }^{1}$

Ampliar las situaciones de intercambio más allá de las puertas del aula es por tanto un propósito central del Club de Lectores: solicitar materiales de lectura a otros compañeros, confrontar opiniones y descubrir nuevos puntos de vista sobre los materiales bibliográficos, informarse sobre la existencia de algún libro interesante...

La presencia de un panel de recomendaciones, es decir, un lugar donde publicar estas apreciaciones e informaciones es un elemento facilitador de los intercambios. Es allí, a la vista de todos, donde los distintos grupos escolares presentan sus opiniones y leen a su vez aquellas que fueron escritas por otros. Por dictado a la maestra o escribiendo por sí mismos en distintos sistemas de escritura -desde producciones presilábicas hasta algunas incursiones alfabéticas- exponen por ejemplo ideas sobre la ilustración, la acción de un personaje interesante o el efecto que les produjo escuchar ciertos pasajes de un texto.

Las maestras propician la lectura de las recomendaciones publicadas para facilitar la comunicación entre los chicos. Ellas leen a sus alumnos las producciones expuestas y éstos deciden si algún material les parece interesante.

"Pete busca llave" es una de las historias sugeridas:

\begin{tabular}{|l}
\hline PETE BUSCA LLAVE \\
$\qquad$\begin{tabular}{l} 
LO RECOMENDAMOS A SALA \\
VERDE PORQUE ES GRACIOSA \\
LA PARTE QUE DICE \\
BUSCO LLAVE TRES VECES \\
SALAAZUL ${ }^{2}$ \\
\hline
\end{tabular} \\
\hline
\end{tabular}


Se trata de la recomendación de un cuento de Graciela Montes, dictada por un grupo de 3 años a su maestra. En ella identifican al potencial lector-los compañeros de 5 años de Sala Verde-, enuncian una frase repetida para justificar su elección y firman el escrito con el nombre de su sala.

Tras la aparente simpleza de esta producción, el proceso de escritura se desarrolla de manera compleja a través de varias clases. Las situaciones de enseñanza propician acciones donde los chicos se enfrentan a diversas prácticas como lectores y escritores: seleccionar un cuento, dictar a un compañero, revisar el texto producido, dictar a la docente la versión final.

Este artículo analiza algunos pasajes de las situaciones didácticas implementadas a fin de ilustrar la manera en que dichas prácticas se comunican tempranamente a los niños.

\section{Selección del texto e intercambio de opiniones.}

"Discutir" sobre los textos para producir recomendaciones escritas es una actividad que puede desarrollarse desde que los niños ingresan al jardín. A través de una secuencia de la clase se advierten algunos de los problemas que enfrenta este grupo de sala de 3 .

La maestra invita a los niños a elegir un cuento para sugerir a otros compañeros del jardín. Para ello propone pensar en los últimos tres libros leídos. Se trata de "El auto de Anastasio", "La bella mariposa" y "Pete busca llave". Muestra los materiales y solicita que recuerden sus títulos. Una vez identificado el libro "La bella mariposa", pregunta por los restantes.

\section{A. Docente}

¿Y este cuál es?(PETE BUSCA LLAVE)

¿Y éste? (EL AUTO DE ANASTASIO).

Saben una cosa, la autora de "Pete

busca llave" y "El auto de Anastasio"

es la misma, es Graciela Montes.

Sí, es cierto, es muy importante como autora de libros para chicos, por eso tenemos tantos...

¿Cuál de estos tres les gustaría recomendar para que los chicos de otra sala los leyeran?

\section{B. Niños}

Paula: Es el de Pete, tenemos más en la biblioteca (refiriéndose a otros libros de la colección).

Este es el de "Pete busca llave".

(Acuerdo generalizado).

Julián: Ese es "El auto de Anastasio".

Martina: Igual que "Federico y el mar", ¡cuántos libros escribió!.

(Algunos piensan que "La bella mariposa", pero la mayoría sostiene que el de Pete es el mejor). 
Como hace unos días que lo leímos, yo no me acuerdo bien qué decía el cuento, no me acuerdo de la parte en que colgaban los globos. ¿Qué les parece si lo vuelvo a leer para ver cómo aparece esto?. Además, vamos a ver si les parece que es este libro el que quieren recomendar; ¿por qué lo quieren recomendar? por ejemplo, si es por el final o por alguna otra parte en especial, si es por algo que dice o cómo lo dice...
Paula: A mí me gustó cuando cuelgan los globos como en un cumpleaños. (Mientras dice esto, el resto de los compañeros la miran, parecen sorprenderse de lo que dice, no entender de qué habla. En realidad, en la historia narrada no existe tal pasaje y sólo se hace referencia a una fiesta. Los globos son parte de la ilustración).

(Todos muestran interés por escuchar el cuento y se mantienen muy atentos durante la lectura de la maestra. Al finalizar aparece el pasaje de la fiesta al que había hecho referencia Paula).

Paula: Ahí era la parte de los globos...pero no dice nada de los globos... (pensativa) dice que hicieron una fiesta. Ah!! Es como en el de "Federico y el mar" (cuento que había sido leído con anterioridad): cuando la mamá le saca la remera a Federico estaba dibujado, pero ahí tampoco decía lo mismo.

(Paula hace referencia a una situación equivalente señalada por ella en otra oportunidad. Allí también había supuesto que el texto decía lo que la imagen exactamente mostraba, hecho que en realidad no sucedía).

Es muy interesante lo que estás descubriendo en este momento. Acá Paula vuelve a pensar sobre lo que está escrito y el dibujo de la hoja (recuerda la situación vivida con el texto "Federico y el mar").

Florencia: Están para la fiesta (refiriéndose a los globos), pero no dice de los globos.

María: Ah...sí... claro.

Martín: "¡Busco llave!. ¡Busco llave!." ( imitando la expresión que reitera el personaje en el transcurso del cuento, y que les había causado mucha gracia cuando la maestra la leía enfáticamente).

Julieta: Y tres veces dice "busco llave", yo las conté así con los dedos (mostrando tres dedos). 
Me parece importante lo que están diciendo: nos podemos detener en esta parte del libro para pensarlo mejor. Martina dice que lo dice la autora y vos decís que no: ¿quién lo dice para vos?
Martina: La autora dice tres veces "busco llave" gritando.

Julieta: Martina, no lo dice la autora.

Julieta: Lo dice Pete, sale a la calle gritando " $¡ B u s c o$ llave! ¡Busco llave!". Pete busca la llave. Sí, es cierto pero yo sigo algo confundida ....ंla autora dice algo en el cuento?

María: Noooo!! La autora lo escribió no lo dijo, sólo lo escribió (lo dice tan segura que el resto no agrega nada al respecto).

En esta breve situación de intercambio para decidir qué recomendar, orientados por la intervención de su maestra los chicos se introducen en el mundo de los autores y sus textos. Comienzan a identificar y a valorar a un escritor a través de sus diferentes obras ("Igual que "Federico y el mar" ¡cuántos libros escribió!", refiriéndose a Graciela Montes ); a discutir sobre las relaciones entre el texto y la ilustración, intentando como Paula superar la idea de que la escritura sea réplica de la información suministrada por la imagen ("Ahi era la parte de los globos (imagen)...pero no dice nada de los globos...dice que hicieron una fiesta...").

En este espacio de intercambio, Martín cita la expresión que le ha resultado más divertida e interesante (";Busco llave!. ;Busco llave!."), una parte que, según agregan Julieta y María aparece de manera repetida ("... tres veces dice 'busco llave', yo las conté así con los dedos"; "La autora dice tres veces 'busco llave' gritando"). ¿Pero quién dice en los textos ficcionales? ¿Cuál es la relación que existe entre la voz del personaje y el autor?. Como se advierte, este es un problema que también en clase la maestra toma y de manera temprana los niños procuran resolver ("..la autora dice..."; "...no lo dice la autora...").

\section{Escritura de la recomendación}

La situación didáctica tiene continuidad en el tiempo. Al día siguiente, los chicos dictan a una de sus compañeras el texto a publicar.

\section{Docente}

Julia va a escribir y el resto del grupo va a dictar. Piensen que tenemos que poner algo que despierte el interés del resto de los chicos, que les dé ganas de leer el libro de Pete. ¿Qué dirá esta recomendación?

¿Qué piensan que tiene que decir para que se entienda, para que se sepa de qué hablamos, para que elijan este libro para leer?

\section{Niños}

(Silencio).

Julieta: El nombre del libro "Pete busca llave". 
Bien, este dato es importante, tiene que estar para que sepan de qué libro se trata.
(Julia escribe PEUAAE con ayuda de varios que dictan algunas letras. En cada una dice lo siguiente: "Pe(P)-te(E)-bus(U)-ca(A)-lla(A)-ve(E)").

Paula: Hay que poner "busco llave".

¿Si ponemos "busco llave" después del título, así se entenderá?

Creo que nosotros lo entendemos porque leímos el libro ¿pero los demás chicos entenderán qué queremos decir? ver si así lo podemos poner en el panel. (Para guardar memoria de la producción realizada, escribe de manera convencional el texto enunciado por los chicos).

Producción lograda por los niños:

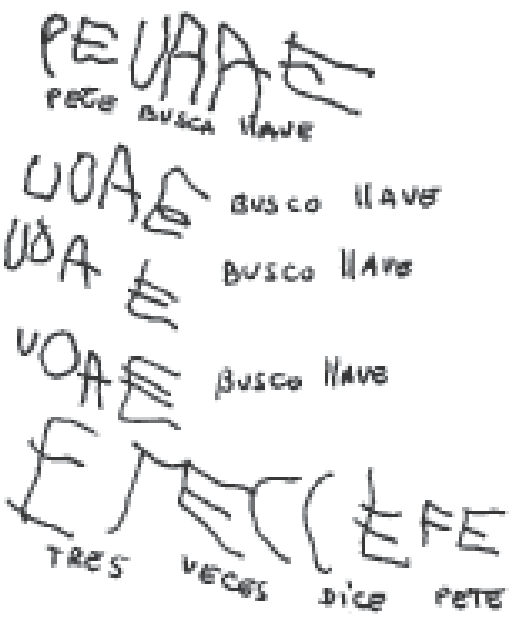

(Sin considerar lo dicho por su maestra, la sugerencia de Paula es tomada como correcta).

María: Tres veces lo dice Pete, así tenemos que ponerlo.

(Todos insisten que ese es el texto que corresponde escribir, a pesar de nuevas intervenciones de la maestra. Por ello Julia, también con ayuda de algunos compañeros, escribe tres veces UOAE considerando que en cada parte dice "bus(U)- co(O)-lla(A)-ve(E)". Para finalizar agrega ESECIEPE por "tres(ES)-ve(E) ces(C)-di(I)-ce(E)-pe(P)-te(E)").

\section{PETE BUSCA LLAVE}

BUSCO LLAVE

BUSCO LLAVE

BUS

CO LLAVE

TRES VECES DICE PETE 
Al día siguiente la maestra relee el escrito y propone acercarse al panel de recomendaciones para saber cómo escriben estos textos los compañeros mayores del jardín. Lee varias escrituras, una de las cuales dice "Lo recomendamos porque es gracioso...". Nuevamente en la sala vuelve a leer el texto de sus alumnos y pregunta si es necesario realizar alguna modificación.

$\mathrm{Al}$ igual que el cuento recomendado por los más grandes, comentan que Pete también es "gracioso", motivo por el cual creen necesario agregar este dato al escrito inicial. Señalan además que las tres escrituras "busco llave" podrían reemplazarse por "...dice 'busco llave' tres veces...". A medida que se suceden estos comentarios -y en este caso para no prolongar la situación- la docente invita a sus alumnos a dictarle el texto definitivo, texto que ha dado apertura a este artículo y en el que pueden reconocerse las transformaciones citadas.

La escritura plantea a estos niños distintos problemas. A través de la intervención de la maestra se presenta como una acción compleja en cuyo proceso deben resolver situaciones de distinta naturaleza: pensar sobre el texto a producir, considerar los destinatarios y los propósitos que la escritura persigue, producir el texto, revisarlo, leer textos similares, volver al propio e intentar mejorarlo.

En el transcurso de estas prácticas de escritura ensayan y comparten distintas respuestas: señalan el título como dato importante a enunciar en la recomendación ("El nombre del libro Pete busca llave") -para ellos un descubrimiento reciente-; consignan como lectores las partes que más impactaron; consideran qué letras y cuántas son necesarias para escribir el texto (en este caso con escritura silábica, un tipo de escritura no predominante en el grupo ); consultan textos producidos por niños más grandes tomando de ellos alguna información; revisan el propio escrito con ayuda de su maestra; reescriben el texto asumiendo la posición de dictantes. En este último caso, a través de la mano de la docente organizan el lenguaje escrito en su versión final. A partir de sucesivos intentos mejoran su producción explicitando el motivo de la recomendación en una frase que lo sintetiza ("...PORQUE ES GRACIOSA LA PARTE QUE DICE BUSCO LLAVE TRES VECES").

A partir de una opinión publicada en el panel de recomendaciones bibliográficas se han expuesto algunas situaciones de enseñanza que suelen permanecer ocultas tras la "simpleza" de la escritura infantil: situaciones de enseñanza planificadas que permiten a los niños actuar como lectores y escritores desde su ingreso al jardín, en un marco de colaboración e intercambio. Un ejemplo más en el cual el jardín de infantes ocupa una función relevante en el largo proceso de alfabetización. 


\section{Notas:}

${ }^{1}$ Molinari, M. C.: "Una actividad permanente: Club de Lectores" (pág. 37). En: CASTEDO, M., MOLINARI, C.; SIRO, A: Enseñar y aprender a leer. Buenos Aires, Ediciones Novedades Educativas, 1999.

El Club de Lectores es una propuesta didáctica que se lleva a cabo con niños de Jardín de Infantes y de Educación General Básica. Es una actividad que cuenta con amplia tradición pedagógica en distintos contextos, desde diferentes perspectivas y diversidad de propósitos. En este trabajo se presenta una de las maneras de entender el Club de Lectores con los niños más pequeños.

Es una Actividad Permanente realizada en el Jardín de Infantes y primeros años de la EGB de la Escuela Graduada "Joaquín V. González" de la Universidad Nacional de La Plata.

Docentes responsables de las producciones y situaciones narradas: Graciela Brena, Guillermina Lanz. Coordinación: M.C. Molinari.

${ }^{2}$ En todos los casos el color de la sala de clase es un recurso que la institución utiliza para diferenciar los distintos grupos escolares.

*Profesora de Ciencias de la Educación, Universidad Nacional de La Plata, Argentina. 